'УО «Гродненский государственный медицинский университет», Гродно, Беларусь ${ }^{2} Г$ ГНУ «Институт генетики и цитологии НАН Беларуси», Минск, Беларусь

Цель исследования: провести сравнительный анализ частот генотипов по аллелям ВsтI (B/b) (rs1544410) и FokI (F/f) (rs2228570) гена VDR в белорусской популящии и у пациентов с CC3 (артериальная гипертензия (АГ), ишемическая болезнь сердия (ИБС)) Гродненского региона.

Материал и методы. Обследованы 182 пациента с CC3. Определение BsmI и FokI гена VDR nроводили методом полимеразной цеепной реакции. Для сравнения использовань результаты анализа генотипов 719 этнических белорусов, в том числе 89 белорусов региона Понеманье.

Результатьл. Генотип bb и аллель b полиморфного локуса BsmI гена VDR чащзе встречался $(p<0,05)$ в группе СС3 (41.2 и 63.2\%, соответственно) и у жителей региона Понеманье (42.9 и 65.3\%, соответственно), чем в общей популяции (31.4 и 56.7\%, соответственно). Жители Гродненского региона с генотипом bbff гена VDR имеют повышенный риск развития ССЗ (ОШ=2,3 (95\% ДИ 1,32; 3,93) и АГ (ОШ с генотипом bbFF гена VDR также имеют повышенный риск развития СС3 (ОШ=1,74 (95\% ДИ 1,06; 2,83) и ИБС (ОШ=2,14 (95\% ДИ 1,14; 4,03).

Bыводы. Установлены достоверные различия в распределении частот генотипов BsmI и FokI гена VDR y пациентов с ССЗ Гродненского региона от общепопуляционных данных.

Ключевые слова: полиморфизм гена VDR, BsmI, FokI, витамин D, артериальная гипертензия, ишемическая болезнь сердияа

\section{Введение}

Открытие рецептора витамина D (VDR) и его последующая идентификация практически во всех тканях организма человека дали новый виток научных исследований в протеомике, раскрывающих регуляторную роль кальцитриола $\left(1,25(\mathrm{OH})_{2} \mathrm{D}_{3}\right)$ в процессах клеточного роста и дифференцировки, ДНК-репарации, апоптоза, иммуномодулирования, ангиогенеза, инициирования системного воспаления посредством активирования более 200 генов в организме человека, а это до 5\% от всего генома $[1,2,3,4]$. VDR, подобно стероидным и другим гормональным рецепторам, является фактором транскрипции, c помощью которого $1,25(\mathrm{OH})_{2} \mathrm{D}_{3}$ регулирует широкий спектр генов, кодирующих как катаболические, так и анаболические процессы в клетке [5]. При этом хорошо изученные эффекты витамина D на гомеостаз кальций-фосфорного обмена в свете последних исследований показали, что среди активируемых VDR генов только небольшая часть регулирует экспрессию белков, вовлеченных в гомеостаз кальция и фосфора. Нечастые патогенные мутации в гене VDR приводят к давно описанному рахиту II типа (1,25-дигидроксивитамин-D-резистентный paхит). К настоящему времени известно более 500 однонуклеотидных замен в гене VDR, встречающихся в популяциях с большой частотой, т.е. относящихся к полиморфным вариантам генетического контекста [6]. Вместе с тем связь между различными патологическими состояниями человека: сердечно-сосудистыми заболеваниями (СС3), нейрокогнитивными, психическими расстройствами, остеопорозом, сахарным диабетом, рядом форм рака и др., наиболее интенсивно исследуется с четырьмя однонуклеотидными заменами гена VDR: BsmI, FokI, TaqI, ApaI [6].

Целью исследования было провести сравнительный анализ частот генотипов по аллелям BsmI (B/b) (rs1544410) и FokI (F/f) (rs2228570) гена VDR в белорусской популяции и у пациентов с СC3 (артериальная гипертензия (АГ), ишемическая болезнь сердца (ИБС)) Гродненского региона.

\section{Материал и методы}

В исследование были включены 182 пациента с СС3 в возрасте от 30 до 79 лет, из них 100 пациентов с АГ ІІ степени в возрасте от 30 до 64 лет (26 мужчин, 74 женщины) и 82 пациента с ишемической болезнью сердца (ИБС), протекающей в сочетании с АГ ІІ степени в возрасте от 35 до 79 лет (36 мужчин, 46 женщин).

На кафедру поликлинической терапии пациенты направлялись терапевтами и кардиологами городских поликлиник № 1-6 г. Гродно по мере обращаемости и при подписании информированного согласия при их соответствии критериям включения/исключения из исследования. Протокол исследования был одобрен комитетом по биомедицинской этике Гродненского государственного медицинского университета. Критерии включения в исследование: наличие эссенциальной АГ II степени [7], в том числе в сочетании с ИБС: стабильной стенокардией напряжения и/или постинфарктным кардиосклерозом. Критерии исключения из исследования: наличие заболеваний, приводящих к вторичной 
АГ (эндокринных, почечных и т.д.), недостаточность кровообращения выше НI, нестабильная стенокардия, хроническая почечная недостаточность, сахарный диабет, прием глюкокортикостероидов, саркоидоз, активная форма туберкулеза легких, онкопатология и другие тяжелые сопутствующие заболевания, способные оказывать влияние на исследуемые параметры.

Выделение ДНК из лейкоцитов цельной венозной крови осуществлялось набором реагентов «ДНК-ЭКСПРЕСС-КРОВЬ» («Литех», Россия) в соответствии с прилагаемой инструкцией.

Определение полиморфного варианта BsmI (B/b) (rs1544410) гена VDR проводили методом полимеразной цепной реакции (ПЦР) с электрофоретической детекцией результата с применением соответствующего набора реагентов производства «Литех» (Россия). Амплификацию исследуемого локуса ДНК проводили на термоциклере Applied Biosystems 2720. Разделение продуктов амплификации осуществляли методом горизонтального электрофореза в 3\% агарозном геле, приготовленном на TAE-буфере и окрашенном Zubr green. Визуализацию и регистрацию ПЦР продуктов осуществляли с помощью системы гель-документирования «Gel Doc XR+ Imaging System».

Существуют общепринятые обозначения аллелей и генотипов по изучаемым полиморфным локусам гена VDR согласно первой букве названия фермента с эндонуклеазной активностью (рестриктазой) по наличию или отсутствию сайта узнавания для этого фермента [8]. Наличие гуанина $(\mathrm{G})$ в локусе rs1544410 обеспечивает узнавание последовательности ферментом BsmI - такой аллель обозначают строчной буквой ' $b$ '. При аденине (A) - сайт узнавания для рестриктазы отсутствует, и аллель обозначают прописной буквой 'В'. Отсутствие сайта узнавания ферментом FokI в локусе rs2228570 свидетельствует о наличии тимина (Т) и, соответственно, аллель обозначают прописной буквой ' $F$ ', а в присутствии цитозина (C) фермент узнает последовательность, разрезает ее, и аллель обозначают строчной буквой ' $\mathrm{f}$ '.

Выявление полиморфного варианта FokI (F/f) (rs2228570) гена VDR проводили методом анализа полиморфизма длин фрагментов, полученных в ходе рестрикции продукта ПЦР (ПЦР-ПДРФ). Для амплификации указанного фрагмента использовали набор реагентов для приготовления реакционной смеси, производства «Синтол» (Россия), и синтетические олигонуклеотиды, производства «Праймтех» (Беларусь): VDR-Fok-F 5'-AGCTGGCCCTGGCACT GACTCTGGCTCT-3' и VDR-Fok-R 5'-ATGGA AACACCTTGCTTCTTCTCCCTC-3'. Реакционную смесь готовили, исходя из расчета на одну пробу: 10 мкл 2,5x реакционной смеси, содержащей 2,5x ПЦР-буфер, $(\mathrm{KCl}$, ТрисHCl $(\mathrm{pH}=8,8)$, $6,25 \mathrm{MM} \mathrm{MgCl}_{2}$ ), SynTaq ДНК-полимеразу, дезоксинуклеозидтрифосфаты, глицерол, Tween 20, 1 мкл раствора $\mathrm{MgCl}_{2}$ (25 мM), 1 мкл каждого праймера (10 мкМ), 5 мкл образца ДНК, 7 мкл деионизированной воды ПЦР-качества. Про- цесс амплификации проводили на термоциклере Applied Biosystems 2720 по следующей программе: начальная денатурация $-95^{\circ} \mathrm{C}, 5$ мин., далее 35 циклов, включающих 20 с денатурацией при $94^{\circ} \mathrm{C}, 40$ - с отжига праймеров при $61^{\circ} \mathrm{C}$, элонгация при $72^{\circ} \mathrm{C}, 30$ с. Завершал процесс амплификации этап финальной элонгации (5 мин. при $72^{\circ} \mathrm{C}$ и охлаждение до $\left.4^{\circ} \mathrm{C}\right)$. Процесс рестрикции полученных ампликонов проводили согласно инструкции набором реагентов производства «Jena Bioscience GmbH» (Германия). Разделение продуктов рестрикции осуществляли методом горизонтального электрофореза в 2\% агарозном геле, приготовленном на ТАЕ-буфере и окрашенном Zubr green. Визуализацию и регистрацию полученного результата осуществляли с помощью системы гель-документирования «Gel Doc XR+ Imaging System».

Кроме того, в работе были использованы результаты анализа генотипов этнических белорусов, проживающих в шести этнографических регионах Беларуси, ДНК которых была собрана сотрудниками (Кушнеревич Е. И., Сивицкой Л. Н., Даниленко Н. Г. и Давыденко О. Г.) в 20042006 гг. лаборатории нехромосомной наследственности Института генетики и цитологии Национальной академии наук Беларуси (ИГЦ НАНБ). Генотипирование белорусов по полиморфным аллелям BsmI (B/b) (rs1544410) и FokI (F/f) (rs2228570) гена VDR проводили с помощь метода ПЦР-ПДРФ [9]. Электронная база данных лаборатории нехромосомной наследственности ИГЦ НАНБ для общей популяционной выборки этнических белорусов, не состоящих в родстве и проживающих в шести регионах страны, составила 719 чел., для выборки этнических белорусов западного региона Беларуси (Понеманье) - 89 человек.

Статистическая обработка результатов осуществлялась с использованием программы «STATISTICA 10.0». Данные представлены в абсолютных числах и в виде \%, сравнение которых проводилось Difference tests между двумя пропорциями. В каждой исследуемой группе проводили оценку соответствия распределения аллелей и генотипов равновесию Харди-Вайнберга. Полученное при этом значение $\mathrm{p}>0,05$ свидетельствовало о выполнении условий данного равновесия. Сравнение распределений эмпирических частот генотипов в популяциях фенотипически здоровых белорусов и в группах пациентов проводилась с использованием программы AB-Stat по методу Хи-квадрат. Для сравнения независимых групп по типу «случай-контроль» с количественной оценкой статистической значимости связи между фактором и исходом рассчитывалось отношение шансов (ОШ) с 95\% доверительным интервалом (ДИ). Статистически значимыми считали различия при значениях $\mathrm{p} \leq 0,05$.

\section{Результаты и обсуждение}

Нами было проведено сравнение распределения частот генотипов по аллелям BsmI и FokI гена VDR между группами пациентов (вся груп- 
па обследованных с СС3 и выделенные группа АГ, группа ИБС) населения Гродненского региона и частотами генотипов в общей популяционной выборке этнических белорусов (719 чел.), проживающих в 6 регионах страны, и частотами генотипов в выборке этнических белорусов (89 чел.) западного региона Беларуси (Понёманье). Результаты анализа представлены в табл. 1 и 2.

Tаблица 1. - Частоты генотипов и аллелей BsmI (B/b) (rs1544410), FokI (F/f) (rs2228570) гена VDR у пациентов с СС3 и в популяции белорусов

\begin{tabular}{|c|c|c|c|c|}
\hline \multirow{2}{*}{\multicolumn{2}{|c|}{$\begin{array}{c}\text { Полиморфный маркер } \\
\text { гена } V D R \\
\text { Группа с CC3 }\end{array}$}} & \multicolumn{3}{|c|}{ Частота (в \%) } \\
\hline & & \multirow{2}{*}{$\begin{array}{c}\begin{array}{c}\text { Популяция } \\
\text { Запада } \\
\text { (Понёманье) }\end{array} \\
41,2^{*}\end{array}$} & \multirow{2}{*}{$\begin{array}{c}\begin{array}{c}\text { Всего в } \\
\text { популяции } \\
\text { Беларуси }\end{array} \\
42,9^{*}\end{array}$} & \multirow[b]{2}{*}{31,4} \\
\hline \multirow[t]{5}{*}{ BsmI } & bb & & & \\
\hline & $\mathbf{B b}$ & 44,0 & 44,9 & 50,7 \\
\hline & BB & 14,8 & 12,2 & 17,9 \\
\hline & Аллель b & $63,2 *$ & $65,3^{*}$ & 56,7 \\
\hline & Аллель В & $36,8^{*}$ & $34,7 *$ & 43,3 \\
\hline \multirow[t]{5}{*}{ FokI } & FF & 33,0 & 19,6 & 29,1 \\
\hline & Ff & 46,1 & 59,8 & 50,3 \\
\hline & ff & 20,9 & 20,7 & 20,6 \\
\hline & Аллель F & 56,0 & 49,5 & 54,2 \\
\hline & Аллель f & 44,0 & 50,5 & 45,8 \\
\hline
\end{tabular}

Примечание: *-статистически значимые различия $(p<0,05)$ со всей популяичией

Как видно из представленных в табл. 1 данных, как в общей популяции Беларуси, в популяции белорусов Понёманья, а также и среди пациентов с СС3 наиболее часто встречался гетерозиготный генотип по обоим полиморфным локусам BsmI (B/b) и FokI (F/f) гена VDR. C наименьшей частотой $(\mathrm{p}<0,0001)$ как в группе пациентов с СС3, так и в популяции, в том числе популяции Запада, встречались генотипы ВВ и ff соответствующих полиморфных локусов гена VDR. Различия по частоте встречаемости между группой пациентов с CC3 и общей популяцией установлены для генотипа bb и частоты аллелей rs1544410 локуса VDR (см. табл. 1). Так, гомозиготный генотип bb и аллель b гена VDR чаще встречался в группе СC3 и в популяции Запада, чем в общей популяции Беларуси $(\mathrm{p}<0,05)$. В свою очередь аллель В полиморфного локуса BsmI гена VDR в группе CC3 и в популяции Запада встречался реже, чем в общей популяции $(\mathrm{p}<0,05)$. Различий по частоте встречаемости других полиморфных генотипов и аллелей BsmI и FokI гена VDR между представленными группами не получено.

Как видно из представленных в табл. 2 данных, с наибольшей частотой как в общей популяции, так и среди пациентов с СС3, в том числе в группах АГ, ИБС, встречался гетерозиготный по обоим аллелям генотип BbFf, кроме популяции белорусов Понёманья, в котором самым частым $(28,1 \%)$ был bbFf генотип. С наименьшей частотой как в группах пациентов, так и в популяции, в том числе популяции Запада, встречался гомозиготный генотип BBff, связанный, по данным ряда исследователей [6], с экспрессией менее активной формы VDR.
Таблица 2. - Частоты генотипов по аллелям BsmI (B/b) (rs1544410), FokI (F/f) (rs2228570) гена VDR у пациентов с СС3 и в популяции белорусов

\begin{tabular}{|c|c|c|c|c|c|c|}
\hline \multirow{2}{*}{ № } & & \multicolumn{5}{|c|}{ Гастота (в \%) } \\
\cline { 3 - 7 } & Генотип & $\begin{array}{c}\text { Группа с } \\
\text { СС3 }\end{array}$ & $\begin{array}{c}\text { Группа с } \\
\text { АГ }\end{array}$ & $\begin{array}{c}\text { Группа с } \\
\text { ИБС }\end{array}$ & $\begin{array}{c}\text { Популяция } \\
\text { Запада } \\
\text { (Понёманье) }\end{array}$ & $\begin{array}{c}\text { Всего в } \\
\text { популяции } \\
\text { Беларуси }\end{array}$ \\
\hline 1 & bbFF & 14,3 & 12,0 & $17,1^{*} \#$ & 6,7 & 8,8 \\
\hline 2 & bbFf & $14,8 \#$ & $16,0 \#$ & $13,4 \#$ & 28,1 & 16,6 \\
\hline 3 & bbff & $12,1 *$ & $15,0^{*}$ & 8,5 & 6,7 & 5,7 \\
\hline 4 & BbFF & 14,3 & 13,0 & 15,9 & 7,9 & 15,4 \\
\hline 5 & BbFf & 23,1 & 24,0 & 22,0 & 25,8 & 24,3 \\
\hline 6 & Bbff & 6,6 & 5,0 & 8,5 & 12,4 & 11,5 \\
\hline 7 & BBFF & 4,4 & 3,0 & 6,1 & 4,5 & 4,5 \\
\hline 8 & BBFf & 8,2 & 10,0 & 6,1 & 5,6 & 10,1 \\
\hline 9 & BBff & 2,2 & 2,0 & 2,4 & 2,3 & 3,1 \\
\hline
\end{tabular}

Примечание: * - статистически значимые различия $(p<0,05)$ при сравнении со всей популяџией, \#-статистически значимые различия $(p<0,05)$ при сравнении с популяцией Западного региона Беларуси (Понёманье)

Генотип bbFF, связанный с экспрессией более активной формы VDR [6], чаще встречался у пациентов с ИБС - 17,1\%, чем во всей популяции Беларуси $-8,8 \%(\mathrm{p}=0,02)$, и чаще, чем в популяции Понеманья - 6,7\% $(\mathrm{p}=0,04)$.

Наиболее часто встречающийся среди белорусов Западного региона генотип bbFf - 28, $1 \%$ - встречался реже у лиц с СС $3-14,8 \%(p=0,01)$ и у пациентов с АГ $-16,0 \%(\mathrm{p}=0,047)$ и ИБС $13,4 \%(p=0,017)$.

Генотип bbff гена VDR чаще встречался среди лиц с CC3 - 12,1\% $(\mathrm{p}=0,005)$ и у пациентов c АГ $-15,0 \%(\mathrm{p}=0,001)$, чем во всей популяции белорусов $-5,7 \%$.

В табл. 3 показаны значения Хи-квадрат, рассчитанные при сравнении эмпирических частот распределения обоих генотипов по аллелям $\operatorname{BsmI}(\mathrm{B} / \mathrm{b})$ и FokI $(\mathrm{F} / \mathrm{f})$ гена VDR в группе всех пациентов с CC3, а также в группах $\mathrm{A}$, ИБС с популяционными частотами белорусов. Статистической достоверности различий между группами пациентов и популяцией Западного региона (Понёманье) не установлено. Частоты генотипов пациентов с ИБС не отличались достоверно от частот в общей популяции Беларуси, тогда как для всей группы пациентов с СС3 (Хи-квадрат $=17,74)$, так и для пациентов с АГ в

Таблица 3. - Значение Хи-квадрат при сравнении частот генотипов по аллелям BsmI (B/b) (rs1544410) и FokI (F/f) (rs2228570) гена VDR пациентов с CC3 c популяционными частотам белорусов

\begin{tabular}{|c|c|c|c|c|}
\hline & $\begin{array}{c}\text { Группа с } \\
\text { АГ }\end{array}$ & $\begin{array}{c}\text { Группа с } \\
\text { ИБС }\end{array}$ & $\begin{array}{c}\text { Группа с } \\
\text { СС3 }\end{array}$ & $\begin{array}{c}\text { Частота вопуляции Запада } \\
\text { (Понёманье) }\end{array}$ \\
\hline Группа с ИБС & 5,62 & & & \\
\hline Группа с СС3 & 1,66 & 2,13 & 15,12 & 11,54 \\
\hline $\begin{array}{c}\text { Частота в } \\
\text { популяции } \\
\text { Запада } \\
\text { (Понёманье) }\end{array}$ & 13,12 & 11,86 & $17,74 *$ & \\
\hline $\begin{array}{c}\text { Всего в } \\
\text { популяции } \\
\text { Беларуси }\end{array}$ & $16,74 *$ & 9,27 & 17,27 & \\
\hline
\end{tabular}

Примечание: *-статистически значимые различия $(p<0,05)$ 
частности (Хи-квадрат=16,74) показаны статистически значимые различия $(\mathrm{p}<0,05)$ по распределению частот генотипов от общепопуляционных данных.

Учитывая установленные различия при сравнении частот генотипов между группами пациентов и популяционными частотами белорусов, нами была проведена оценка отношения шансов, которая показала, что лица с генотипом bbff гена VDR имеют в 2,3 раза выше риск развития CC3 $(О Ш=2,3(95 \%$ ДИ 1,32; 3,93) и в 2,92 раза выше риск развития АГ (ОШ $=2,92$ (95\% ДИ 1,55; $5,496)$, чем люди с другими генотипами в белорусской популяции. В свою очередь обладатели генотипа $\mathrm{bbFF}$ гена VDR имеют в 1,7 раза выше риск развития СС3 (ОШ=1,74 (95\% ДИ 1,06; 2,83) и в 2,14 раза выше риск развития ИБС $(\mathrm{ОШ}=2,14$ (95\% ДИ 1,14; 4,03), чем носители других генотипов белорусской популяции. Кроме того, обладатели генотипа bbFF гена VDR имеют в 2,85 раза выше риск развития ИБС, чем этнические белорусы Западного региона по сравнению с носителями других генотипов (ОШ=2,85 (95\% ДИ $1,04 ; 7,81)$.

Исследования популяционных частот генотипов полиморфных вариантов гена VDR coдействуют более корректной оценке их вклада в риск развития заболеваний в каждой конкретной стране или регионе. Частота встречаемости полиморфных аллелей BsmI, FokI, TaqI, ApaI гена VDR в популяции Беларуси ранее была описана группой соавторов статьи [10]. Нами впервые проведено сопоставление частоты генотипов и аллелей по полиморфным вариантам BsmI и FokI гена VDR у пациентов с CC3 Гродненского региона и популяционными частотами как в Беларуси в целом, так и в Западном регионе в частности. Ранее нами было указано, что ни в группе с АГ, ни в группе с ИБС генетическая структура групп не зависит от пола и не различается между мужчинами и женщинами по частоте встречаемости генотипов BsmI и FokI гена VDR [11]. В свете результатов, изложенных выше, хочется обратить внимание врачей первичного звена здравоохранения, наиболее активно работающих с пациентами по вопросам первичной профилактики СС3, что для персонифицированной оценки риска развития СС3, особенно АГ, ИБС, жителям Гродненского региона следует рекомендовать анализ ПЦР гена VDR по полиморфным вариантам BsmI и FokI, с учетом полученных нами данных, указывающих, что с генотипом bbff и bbFF риск развития CC3 повышен в 2-3 раза.

Полученные нами результаты согласуются с данными литературы, указывающими на ассоциацию риска развития СС 3 , а именно АГ, ИБС с полиморфизмом BsmI и/или FokI гена VDR [12,
$13,14,15,16]$. Так, в крупном (n=1211) проспективном исследовании американских мужчин с длительностью наблюдения в среднем 15,3 года, риск АГ составил 1,25 (1,04-1,51) для генотипа BsmI bb по сравнению с генотипом bB или BB гена VDR. Для VDR FokI генотипа FF и Ff риск развития АГ составил $1,32(1,03-1,70)$ по сравнению с генотипом ff [16]. Сравнение генотипов 200 здоровых лиц и 280 пациентов с АГ в Индии по полиморфизму FokI гена VDR также установило повышенный риск развития АГ при генотипе $\mathrm{FF}$ и аллеле $\mathrm{F}$ для лиц обоих полов, с отягощенной наследственностью и курением [15]. В испанском исследовании было показано, что BsmI полиморфизм гена VDR влияет на apтериальное давление (АД) у здоровых мужчин, которые при bb генотипе имеют выше уровень систолического АД по сравнению с другими генотипами [12]. Результаты исследования корейских рабочих выявили противоположные данные, указывающие, что значения систолического и диастолического АД, распространенность АГ выше у лиц с генотипами ВВ и $\mathrm{Bb}$ по сравнению с генотипом bb [13]. У лиц моложе 65 лет $(\mathrm{n}=1946)$ с генотипом ВВ полиморфного локуса BsmI гена VDR имелся повышенный риск развития инфаркта миокарда (ОШ 1.38 (95\% ДИ 1.071.79; p=0.016) [14]. Приведенные литературные данные указывают на очевидную роль генотипов BsmI и FokI гена VDR в развитии как $А Г$, так и ИБС, однако имеющиеся различия в полученных результатах в разных странах указывают на необходимость проведения собственных популяционных и региональных исследований.

\section{Выводы}

1. Генотип bb и аллель b полиморфного локуса BsmI гена VDR чаще встречался в группе с CC3 и в популяции жителей западного региона Беларуси, чем в общей популяции.

2. Установлены достоверные различия в распределении частот генотипов BsmI и FokI гена VDR у пациентов с CC3, в том числе с АГ, Гродненского региона от общепопуляционных данных.

3. Жители Гродненского региона с генотипом bbff гена VDR имеют повышенный риск развития СС3 (ОШ=2,3 (95\% ДИ 1,32; 3,93) и АГ $(О Ш=2,92$ (95\% ДИ 1,55; 5,496).

4. Жители Гродненского региона с генотипом bbFF гена VDR также имеют повышенный риск развития СС3 $(\mathrm{OШ}=1,74(95 \%$ ДИ 1,$06 ; 2,83)$ и ИБС (ОШ=2,14 (95\% ДИ 1,14; 4,03). Кроме того, обладатели генотипа bbFF имеют выше риск развития ИБС, чем этнические белорусы Западного региона $(О Ш=2,85(95 \%$ ДИ 1,$04 ; 7,81)$ по сравнению с носителями других генотипов.

\section{Литература}

1. Громова, О. А. Витамин Д - смена парадигмы / О. А. Громова, И. Ю. Торшин. - Москва : Торус-пресс, 2015. -463 c.

2. Значение витамина D в патогенезе сердечно-сосуди-

стых заболеваний / В. В. Поворознюк [и др.] // Журнал Гродненского государственного медицинского университета. - 2015. - № 2 (50). - C. 6-14.

3. Holick, M. F. The vitamin D deficiency pandemic and consequences for nonskeletal health: mechanisms of 
action / M. F. Holick // Molecular Aspects of Medicine. 2008. - Vol. 29 (6). - P. 361-368.

4. Norman, A. W. Vitamin D Receptor: New Assignments for an Already Busy Receptor / A. W. Norman // Endocrinology. - 2006. - Vol. 147 (12). - P. 5542-5548. - doi: 10.1016/j.mam.2008.08.008.

5. Pike, J. W. Regulation of gene expression by 1,25-dihydroxyvitamin D3 in bone cells: exploiting new approaches and defining new mechanisms / J. W. Pike, S. M. Lee, M. B. Meyer // BoneKEy Reports. - 2014. - Vol. 3. - Art. nr. 482. - doi: 10.1038/bonekey.2013.216.

6. Genetics and biology of vitamin D receptor polymorphisms / A. G. Uitterlinden [et al.] // Gene. - 2004. - Vol. 338 (2). - P. 143-156.

7. ESH/ESC Guidelines for the management of arterial hypertension/ G. Mancia [et al.] // Journal of Hypertension. - 2013. - Vol. 31 (7). - P. 1281-1357. - doi: 10.1097/01. hjh.0000431740.32696.cc.

8. Vitamin D receptor gene FokI but not TaqI, ApaI, BsmI polymorphism is associated with Hashimoto's thyroiditis: a meta-analysis / X. Wang [et al.] // Scientific Reports. 2017. - Vol. 7. - Art. nr. 41540. - doi: 10.1038/srep41540.

9. Association between vitamin D receptor gene haplotypes and chronic periodontitis among Japanese men / M. Naito [et al.] // International Journal of Medical Sciences. 2007. - Vol. 4 (4). - P. 216-222. - doi:10.7150/ijms.4.216.

10. Особенности распределения частот полиморфных аллелей гена рецептора витамина D в популяциях этнических белорусов / Е. А. Аксенова [и др.] // Молекулярная и прикладная генетика : сб. науч. тр. / Государственное научное учреждение "Институт генетики и цитологии НАН Беларуси" ; ред. А. В. Кильчевский [и др.]. - Минск : Институт генетики и цитологии НАН Беларуси, 2016. - Т. 21. - С. 71-80.

11. Influence of the vitamin D receptor gene polymorphisms and 25-hydroxyvitamin D on blood pressure in apparently healthy subjects / S. Muray [et al.] // Journal of Hypertension. - 2003. - Vol. 21 (11). - P. 2069-2075. doi: 10.1097/01.hjh.0000098139.70956.21.

12. Associations of blood pressure and hypertension with lead dose measures and polymorphisms in the receptor $\delta$-aminolevulinic acid dehydratase genes / B. K. Lee [et al.] // Environmental Health Perspectives. 2001. - Vol. 109 (4). - P. 383-389. - doi: 10.1097/01. hjh.0000098139.70956.21.

13. Additive effects of the chemokine receptor 2, vitamin D receptor, interleukin-6 polymorphismsand cardiovascular risk factors on the prevalence of myocardial infarction in patients below 65 years / J. R. Ortlepp [et al.] // International Journal of Cardiology. - 2005 - Vol. 105 (1). - P. 90-95. - doi: 10.1016/j.ijcard.2005.03.004.

14. Risk conferred by FokI polymorphism of vitamin D receptor gene for essential hypertension / N. Swapna [et al.] // Indian Journal of Human Genetics. - 2011. - Vol. 17 (3). - P. 201-206. - doi: 10.4103/0971-6866.92104.

15. A prospective study of plasma vitamin D metabolites, vitamin D receptor gene polymorphisms, and risk of hypertension in men / L. Wang [et al.] // European Journal of Nutrition. - 2013. - Vol. 52 (7). - P. 1771-1779. - doi: 10.1007/s00394-012-0480-8.

\section{References}

1. Gromova OA, Torshin IJu. Vitamin D - smena paradigmy [Vitamin D - paradigm change]. Moskva: Torus-press; 2015. 463 p. (Russian).

2. Povoroznyuk VV, Snezhitskiy VA, Yankouskaya
LV, Maylyan EA, Reznichenko NA, Maylyan DE. Extraskeletal effects of vitamin D: role in the pathogenesis of cardiovascular diseases. Journal of the Grodno State Medical University. 2015;2(50):6-14. (Russian).

3. Holick MF. The vitamin D deficiency pandemic and consequences for nonskeletal health: mechanisms of action. Molecular Aspects of Medicine. 2008;29:361-368.

4. Norman AW. Vitamin D Receptor: New Assignments for an Already Busy Receptor. Endocrinology. 2006;147(12):5542-5548.

5. Pike JW, Lee SM, Meyer MB. Regulation of gene expression by 1,25 -dihydroxyvitamin D3 in bone cells: exploiting new approaches and defining new mechanisms. BoneKEy Reports. 2014;3:Art No 482. doi:10.1038/ bonekey.2013.216.

6. Uitterlinden AG, Fang Y, Van Meurs JB, Pols HA, Van Leeuwen JP. Genetics and biology of vitamin D receptor polymorphisms. Gene. 2004;338:143-156.

7. Mancia G, Fagard R, Narkiewicz K, Redón J, Zanchetti A, Böhm M, Christiaens T, Cifkova R, De Backer G, Dominiczak A, Galderisi M, Grobbee DE, Jaarsma T, Kirchhof P, Kjeldsen SE, Laurent S, Manolis AJ, Nilsson PM, Ruilope LM, Schmieder RE, Sirnes PA, Sleight P, Viigimaa M, Waeber B, Zannad F. ESH/ESC Guidelines for the management of arterial hypertension. Journal of Hypertension. 2013;31(7):12810-1357. doi: 10.1097/01. hjh.0000431740.32696.cc.

8. Wang X, Cheng W, Ma Y, Zhua J. Vitamin D receptor gene FokI but not TaqI, ApaI, BsmI polymorphism is associated with Hashimoto's thyroiditis: a meta-analysis. Scientific Reports. 2017;7:Art No 41540. doi:10.1038/ srep41540.

9. Naito M, Miyaki K, Naito T, Zhang L, Hoshi K, Hara A, Masaki K, Tohyama S, Muramatsu M, Hamajima N, Nakayam T. Association between vitamin $\mathrm{D}$ receptor gene haplotypes and chronic periodontitis among Japanese men. International Journal of Medical Sciences. 2007;4(4):216222. doi: 10.7150/ijms.4.216.

10. Aksenova EA, Silvanovich AP, Mihajlovskaja AV, Danilenko NG. Osobennosti raspredelenija chastot polimorfnyh allelej gena receptora vitamina $\mathrm{D} v$ populjacijah jetnicheskih belorusov [Peculiarities of VDR gene polymorphic allele frequencies in populations of native belarusians]. In: Kilchevskij AV, editor. Molekuljarnaja i prikladnaja genetika [Molecular and Applied Genetics] : sbornik nauchnyh trudov. Minsk: Institute of Genetics and Cytology of the National Academy of Sciences of Belarus; 2016;21:71-80. (Russian).

11. Muray S, Parisi E, Cardús A, Craver L, Fernández E. Influence of the vitamin D receptor gene polymorphisms and 25-hydroxyvitamin D on blood pressure in apparently healthy subjects. Journal of Hypertension. 2003;21(11):2069-2075. doi: 10.1097/01. hjh.0000098139.70956.21.

12. Lee BK, Lee GS, Stewart WF, Ahn KD, Simon D, Kelsey KT, Todd AC, Schwartz BS. Associations of blood pressure and hypertension with lead dose measures and polymorphisms in the receptor $\delta$-aminolevulinic acid dehydratase genes. Environmental Health Perspectives. 2001;109(4):383-389. doi: 10.1097/01. hjh.0000098139.70956.21.

13. Ortlepp JR, Krantz C, Kimmel M, von Korff A, Vesper K, Schmitz F, Mevissen V, Janssens U, Franke A, Hanrath P, Zerres K, Hoffmann R. Additive effects of the chemokine receptor 2, vitamin D receptor, interleukin-6 polymorphismsand cardiovascular risk factors on 
the prevalence of myocardial infarction in patients below 65 years. International Journal of Cardiology. 2005;105(1):90-95. doi: 10.1016/j.ijcard.2005.03.004.

14. Swapna N, Vamsi UM, Usha G, Padma T. Risk conferred by FokI polymorphism of vitamin D receptor gene for essential hypertension. Indian Journal of Human Genetics.
2011;17(3):201-206. doi: 10.4103/0971-6866.92104.

15. Wang L, Ma J, Manson JE, Buring JE, Gaziano JM, Sesso HD. A prospective study of plasma vitamin D metabolites, vitamin $\mathrm{D}$ receptor gene polymorphisms, and risk of hypertension in men. European Journal of Nutrition. 2013;52(7):1771-1779. doi: 10.1007/s00394-012-0480-8.

\title{
COMPARATIVE ANALYSIS OF VITAMIN D RECEPTOR GENOTYPE FREQUENCIES IN BELARUSIAN POPULATION AND IN PATIENTS WITH CARDIOVASCULAR DISEASES OF GRODNO REGION
}

${ }^{\prime}$ Yankouskaya L. V., ${ }^{2}$ Aksyonova E. A., 'Snezhitskiy V. A., ${ }^{2}$ Danilenko N. G., 'Stepuro T. L.

\author{
1 Educational Institution "Grodno State Medical University, Grodno, Belarus
}

2 State Scientific Institution "Institute of Genetics and Cytology of NAS of Belarus"

The aim of the study was to perform a comparative analysis of the frequencies of genotypes by BsmI (B / b) (rs 1544410) and FokI (F/f) (rs2228570) alleles of the VDR gene in Belarusian population and in patients with CVD (arterial hypertension (AH), ischemic heart disease (IHD)) of Grodno region.

Material and methods. 182 patients with CVD were examined. BsmI and FokI of the VDR gene were determined by polymerase chain reaction. For comparison, the results of the genotypes analysis of 719 ethnic Belarusians, including 89 Belarusians of Ponemanje region, were used.

Results. Genotype $b b$ and allele $b$ of polymorphic BsmI locus of the VDR gene were more frequent $(p<0.05)$ in the group with CVD (41.2\% and $63.2 \%$, respectively) and in citizens of Ponemanje region $(42.9 \%$ and $65.3 \%$, respectively) than in general population (31.4\% and 56.7\%, respectively). Patients from Grodno region with genotype bbff of the VDR gene have an increased risk of developing CVD $(O R=2.3(95 \%$ CI 1.32, 3.93) and AH $(O R=2.92$ (95\% CI 1.55, 5.496), patients with genotype bbFF also have an increased risk of developing CVD (OR $=1.74(95 \%$ CI 1.06, 2.83) and CHD (OR $=2.14$ (95\% CI 1.14, 4.03).

Conclusions: Significant differences in frequency distribution of genotypes BsmI and FokI of the VDR gene in patients with CVD of Grodno region compared to general population data were established.

Keywords: polymorphism of VDR gene, BsmI, FokI, vitamin D, arterial hypertension, ischemic heart disease 